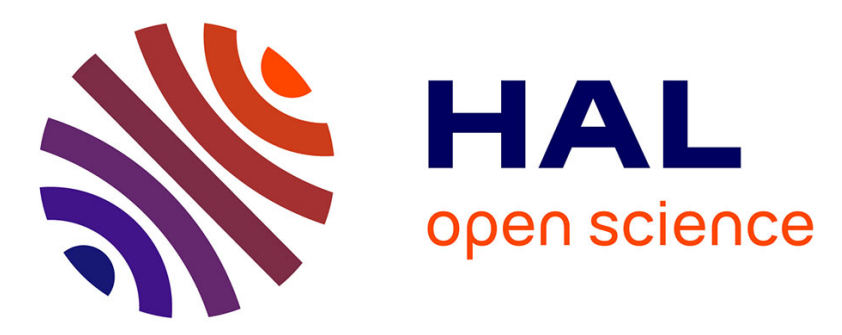

\title{
Static and dynamic electronic characterization of organic monolayers grafted on a silicon surface
}

Olivier Pluchery, Y. Zhang, R. Benbalagh, L. Caillard, J. J. Gallet, F. Bournel, A.-F. Lamic-Humblot, M. Salmeron, Y. J. Chabal, F. Rochet

\section{To cite this version:}

Olivier Pluchery, Y. Zhang, R. Benbalagh, L. Caillard, J. J. Gallet, et al.. Static and dynamic electronic characterization of organic monolayers grafted on a silicon surface. Physical Chemistry Chemical Physics, 2016, 18 (5), pp.3675-3684. 10.1039/C5CP05943G . hal-01262800

\section{HAL Id: hal-01262800 https://hal.sorbonne-universite.fr/hal-01262800}

Submitted on 27 Jan 2016

HAL is a multi-disciplinary open access archive for the deposit and dissemination of scientific research documents, whether they are published or not. The documents may come from teaching and research institutions in France or abroad, or from public or private research centers.
L'archive ouverte pluridisciplinaire HAL, est destinée au dépôt et à la diffusion de documents scientifiques de niveau recherche, publiés ou non, émanant des établissements d'enseignement et de recherche français ou étrangers, des laboratoires publics ou privés. 


\title{
Journal Name
}

\section{ARTICLE}

\author{
Article Published in Physical Chemistry Chemical Physics, 2016, \\ DOI: 10.1039/C5CP05943G
}

Received 00th January 20xx, Accepted 00th January 20xx DOI: $10.1039 / \times 0 \times x 00000 x$ www.rsc.org/

\section{Introduction}

Molecular electronics offers new strategies for downscaling integrated circuit devices. ${ }^{1}$ On the one hand, single-molecule experiments strive to investigate the fundamental phenomena when electrons are driven through a single molecule. ${ }^{2-5}$ On the other hand, a layer of organic molecules can provide a unique connection to the existing silicon-based electronics, and be used to perform specific functions such as diodes, resonant tunnel diodes, memories or transistors. Unfortunately, the

\footnotetext{
a. Sorbonne Universités, UPMC Univ Paris 06, CNRS-UMR 7588, Institut des NanoSciences de Paris, F-75005, Paris, France

b. Materials Sciences Division, Lawrence Berkeley National Laboratory, Berkeley, CA 94720, USA.

Applied Science and Technology Graduate Program, University of California at Berkeley, Berkeley, CA 94720, USA.

${ }^{d .}$ Sorbonne Universités, UPMC Univ Paris 06, CNRS-UMR 7614, Laboratoire de Chimie Physique, Matière et Rayonnement, F-75005, Paris, France

e. Laboratory for Surface and Nanostructure Modification, Department of Materials Science and Engineering, University of Texas at Dallas, 800 West Campbell Road, Dallas, Texas 75080 , USA

f. Sorbonne Universités, UPMC Univ Paris 06, CNRS-UMR 7197, Laboratoire de Réactivité de Surface, F-75005 Paris, France.
}

Electronic Supplementary Information (ESI) available: chemical preparation of the GOM and of the gold nanoparticles, other STM and c-AFM images, calculation of the surface sensitivity of XPS, XPS Au $4 f$ core-level spectra, additional UPS spectra, useful parameters for band bending calculation. See DOI: 10.1039/x0xx00000x interface of silicon $(\mathrm{Si})$ is often affected by oxidation and it is extremely challenging to prepare a silicon-molecule interface with tailored and defect-free electronic characteristics. ${ }^{6-9}$ Even more challenging is to fabricate metal-insulator-semiconductor (MIS) junctions with an organic monolayer as the insulating layer. ${ }^{10,11}$ In the past fifteen years, several chemical methods have been proposed for functionalizing silicon surfaces with highly ordered organic monolayers. Hydrosilylation involves the reaction of oxide-free, $\mathrm{H}$-terminated $\mathrm{Si}$ surfaces with alkene functionality. This enables the grafting of alkyl chains molecules to form a stable $\mathrm{Si}-\mathrm{C}$ bond using several different activation processes: thermal, catalytic, photochemical or radicals. ${ }^{12-16}$ The mechanisms at play for this reaction are now well established, ${ }^{17-20}$ and the properties offered by such Grafted Organic Monolayers (GOMs) are harvested for a number of applications. An alternative method, based on supercritical carbon dioxide, has also been used to prepare organic layers on oxide -free $\mathrm{Si}^{21,22} \mathrm{~A}$ few devices have already been proposed, based on GOM/Si heterostructures, such as organic memories, ${ }^{23}$ ideal Schottky diodes, ${ }^{9}$ organic photovoltaic solar cells, ${ }^{24}$ biological sensors, ${ }^{25,}{ }^{26}$ and doubletunnel junctions for Coulomb blockade. ${ }^{27}$

GOMs are highly ordered organic layers, in which structural homogeneity leads to spatially homogeneous electronic properties and well-defined band structures. For these 
sensitive applications, these ultrathin molecular layers have to meet several requirements: (1) chemical: to protect the silicon substrate from oxidation and minimize the formation of interface states especially during post-processing steps, (2) dielectric: to function well as rectifier, Schottky barrier, tunnel junction, and (3) linker: to connect another electrode (thin film or nanoscale electrode). In this context, it is crucial to precisely evaluate the work function, amount of surface defects, band bending throughout the processing steps and ensure they meet the expected electronic requirements.

Different molecules have been investigated in the last ten years, and the band diagram of the corresponding monolayers was established with X-ray photoemission spectroscopy (XPS), ultraviolet photoemission spectroscopy (UPS), ${ }^{28-33}$ and Kelvin probe force microscopy (KPFM) ${ }^{34,35}$.

In the present work we focus on two types of GOMs with different thicknesses that can each act as a tunnel junction. We also chemically post-modify the layer with an amine moiety, making it possible to attach gold nanoparticles, i.e. nanoscale electrodes, acting as a non-planar MIS junction. We have already shown that this structure exhibits Coulomb blockade under the tip of a scanning tunneling microscope (STM). ${ }^{27,36}$ In the present study, we monitor the dependence of the main electric parameters of the interface (band bending, work function, LUMO edge) on each processing step of their chemical preparation. We also measure and describe the transport regime through these tunnel junctions by using conductive atomic force microscopy (c-AFM).

\section{Experimental section}

\section{Material and methods}

The samples are obtained from $\mathrm{Si}(111)$ monocrystals, doped $\mathrm{n}+$ with a resistivity of $0.01 \mathrm{Ohm} . \mathrm{cm}$ (dopant concentration of $2 \times 10^{18} \mathrm{~cm}^{-3}$ ) and with a miscut of $0.5^{\circ}$ in the $\langle\overline{112}\rangle$ direction. They are cut into $10 \times 8 \mathrm{~mm}^{2}$ pieces and prepared by wet chemical methods in a $\mathrm{N}_{2}$-purged glovebox (amount of water and oxygen below $1 \mathrm{ppm}$ ) following a well-established protocol $^{12-16,20}$ described in our previous studies. ${ }^{27,36,37}$ (see also ESI for additional details) Briefly, the Si substrates are cleaned with a Piranha solution, then in an $\mathrm{NH}_{4} \mathrm{~F}$ solution to produce atomically flat, $\mathrm{H}$-terminated $\mathrm{Si}(111)$ surfaces ${ }^{38}$ Next, two different alkene molecules (with different alkyl chain lengths) are used to organic monolayers (GOM) by hydrosilylation, denoted $\mathrm{SiC}_{11}$-COEth and $\mathrm{SiC}_{7}$-COEth (Figure 1a and Figure 1-d). The long GOM, ethyl-undecylenate, is reacted with $\mathrm{H}-\mathrm{Si}(111)$ by thermal hydrosilylation at $200^{\circ} \mathrm{C}^{37}$ while the short GOM, ethyl-heptenoate, is grafted by UV activation. ${ }^{27}$ These two surfaces are terminated with an ester and can be modified following a two-step procedure. In the first step the ester is deprotected into a carboxylic moiety; in the second step, this termination is reacted with $\mathrm{N}$ hydroxysuccinimyl (NHS) to obtain an amine. These two surfaces are depicted in Figure 1-b and Figure 1-e and termed $\mathrm{SiC}_{11}-\mathrm{NH}_{2}$ and $\mathrm{SiC}_{7}-\mathrm{NH}_{2}$. The amine group is essential to attach gold nanoparticles through direct amine-gold bonding. The fully reacted surfaces, with Au nanoparticles, remain stable enough in an Ar-filled plastic container for shipping from Texas to France (for XPS, STM and AFM characterization) and to California (for conductive AFM measurements).

Gold nanoparticles (AuNPs) are prepared as a colloidal solution from reduction of $\mathrm{HAuCl}_{4}$ by ascorbic acid ${ }^{27,36,39,40}$ (details in the ESI). The amine terminated surfaces are dipped into the colloidal solution for about $10 \mathrm{~min}$ after the solution was acidified at $\mathrm{pH}^{\sim}$. The amine is protonated, which enables the attachment of AuNPs. The surface density is measured with AFM and found to be $7 \times 10^{9} \mathrm{AuNP} / \mathrm{cm}^{2} 27,36$. TEM measurements have shown that the AuNPs are spherical and with an average diameter of $8.2 \mathrm{~nm}$ and a size dispersion of $4.0 \mathrm{~nm}$, which allows Coulomb blockade experiments. ${ }^{27,}{ }^{36} \mathrm{We}$ estimate that $0.3 \%$ of the surface is covered with gold (average distance between AuNPs is $120 \mathrm{~nm}$ ). The two AuNPfunctionalized surfaces depicted in Figure 1-c and Figure 1-f are labeled $\mathrm{C}_{11} \mathrm{NH}_{2}-\mathrm{AuNP}$ and $\mathrm{C}_{7} \mathrm{NH}_{2}$-AuNP.

(a) $\mathrm{C}_{11}$ COEth

(b) $\mathrm{C}_{11} \mathrm{NH}_{2}$

(c) $\mathrm{C}_{11} \mathrm{NH}_{2}$-AuNP
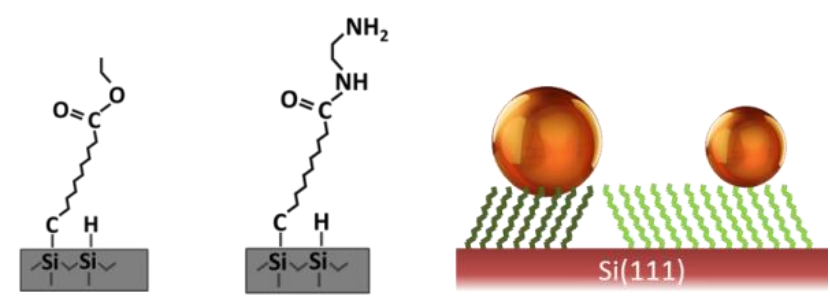

(d) $\mathrm{C}_{7}$ COEth

(e) $\mathrm{C}_{7} \mathrm{NH}_{2}$

(f) $\mathrm{C}_{7} \mathrm{NH}_{2}$-AuNP
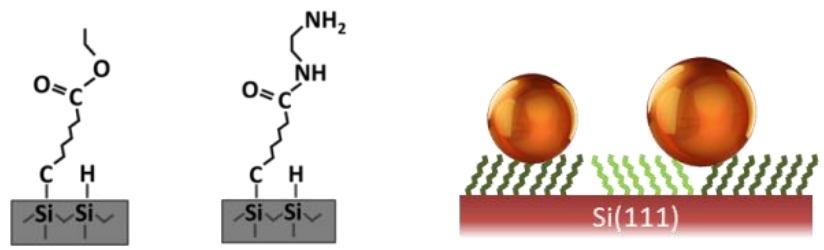

Figure 1. Sketch of the six samples used in the present study. The molecules are closely packed and protect the $\mathrm{Si}(111)$ substrate against oxidation. Two alkyl chains were grafted ( $\mathrm{C7}$ and $\mathrm{C} 11)$ and two terminations were prepared. Gold nanoparticles were deposited on the amine terminated surfaces.

\section{Instrumentation}

STM was used to check the quality of the GOM, performed in an UHV chamber (base pressure $3 \times 10^{-11} \mathrm{mbar}$ ) after the surface was annealed in vacuum at $150^{\circ} \mathrm{C}$ for $30 \mathrm{~min}$. This procedure removes the physisorbed molecules (mostly water) and stabilizes the STM imaging conditions. Importantly it does not alter the organic layer as revealed by infrared absorption measurements ${ }^{27,37}$

X-Ray Photoelectron Spectroscopy (XPS) was carried in UHV conditions and the core-level spectra were measured with a non-monochromatized Al $\mathrm{K} \alpha$ source ( $\mathrm{h} v=1486.61 \mathrm{eV}$ for the main $\mathrm{Al} \mathrm{K \alpha _{1,2 }}$ line). The takeoff angle of the photoelectrons was normal to the surface. The overall energy resolution was $0.85 \mathrm{eV}$ (source and analyzer). For UV photoemission spectroscopy (UPS) measurements, the UV source was the He I line $(\mathrm{hv}=21.21 \mathrm{eV})$ and a spectral resolution of $50 \mathrm{meV}$ was achieved. Binding energies (BE) and kinetic energies (KE) are 
referenced with respect to the Fermi level. The Fermi edge is determined via UV photoemission spectroscopy of a freshly sputtered (unannealed) polycrystalline gold foil. Work functions are determined by measuring the cutoff of the secondary electron edge (see below).

Conductive AFM measurements were performed in an UHV chamber (base pressure $5 \times 10^{-9}$ torr) to measure the transport properties of the GOMs. The AFM measurements were carried out with a $\mathrm{Cr} / \mathrm{Pt}$ tip on samples previously annealed for $30 \mathrm{~min}$ at $120^{\circ} \mathrm{C}$ in vacuum. Finally, AFM was also used in contact mode to record the topography of the samples and to record I-V data on selected points.

\section{Results}

\section{Morphology of the GOM surface (STM)}

Figure 2 shows STM images of the $\mathrm{C}_{7}-\mathrm{NH}_{2}$ surface. This $100 \times 100 \mathrm{~nm}^{2}$ image remains stable, as expected for a compact and homogeneous GOM monolayer. The surface exhibits circular spots (inset of Figure 2) of typically $4 \mathrm{~nm}$ diameter due to small domains of molecules in which the $\mathrm{C}_{7}$ alkyl chains are tilted in the same direction with respect to the surface, as schematically shown in Figure $\mathbf{1} \mathrm{c}$ and $\mathrm{f}$.

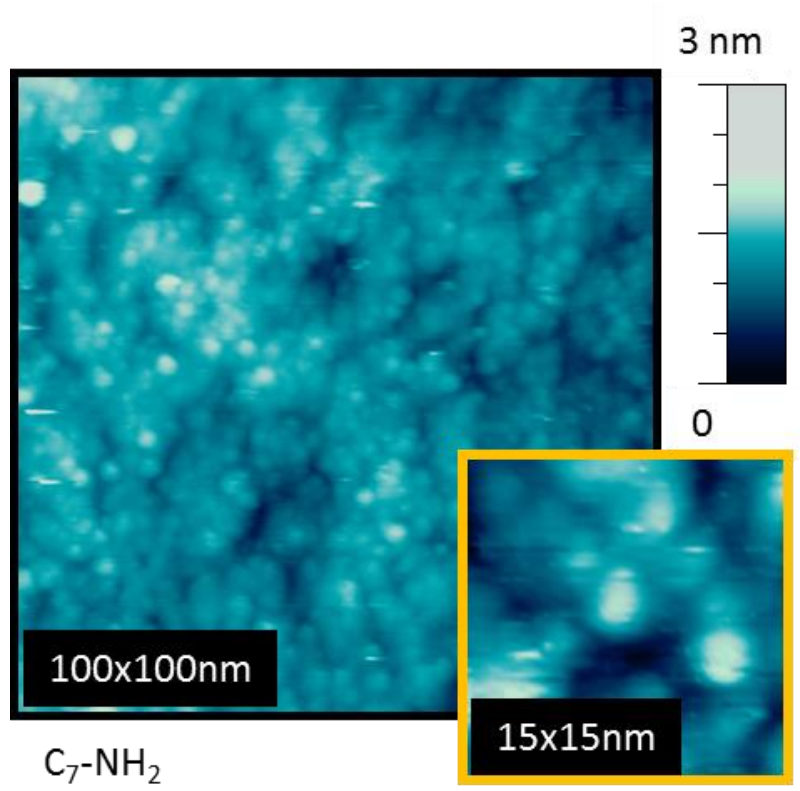

Figure 2. STM image $(100 \times 100 \mathrm{~nm})$ of the $\mathrm{C}_{7}-\mathrm{NH}_{2}$ molecular layer grafted on $\mathrm{Si}(111$ recorded at room temperature under a sample bias of $-2 \mathrm{~V}$. The surface was annealed at $150^{\circ} \mathrm{C}$ for $30 \mathrm{~min}$ before scanning. Molecules are organized in bundles of $\sim 4 \mathrm{~nm}$ diameter (inset).

GOMs with long chain molecules, $\mathrm{C}_{11}-\mathrm{NH}_{2}$ also yield stable STM images similar to those in Figure 2 (see ESI), consistent with good molecular organization. The thickness of the amineterminated monolayers, measured by ellipsometry, is $1.3 \mathrm{~nm}$ for $\mathrm{C}_{7}-\mathrm{NH}_{2}$ and $1.6 \mathrm{~nm}$ for $\mathrm{C}_{11}-\mathrm{NH}_{2} \cdot{ }^{27,37}$

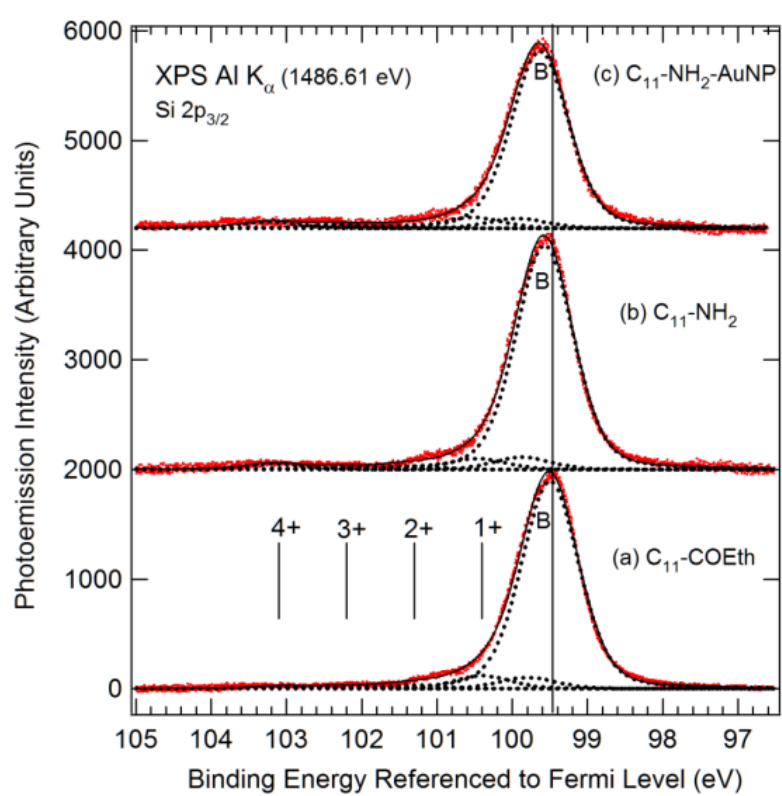

Figure 3. Si $2 p_{3 / 2}$ core-level peaks from XPS experiments (red dots) of the (a) $\mathrm{C}_{11}$-COEth (b) $\mathrm{C}_{11}-\mathrm{NH}_{2}$ and (c) $\mathrm{C}_{11}-\mathrm{NH}_{2}$ AuNP grafted organic monolayers. Fits are made with sums of pseudo-Voigt curves (see text) and several contributions are highlighted. The main peak from the bulk is denoted $B$. The four oxidation states of silicon are indicated from $1+$ to $4+$. The position of peak $B$ is used for measuring the surface band bending in our samples using the fact that the energy distance between the valence band maximum and the $\mathrm{Si} 2 \mathrm{p}_{3 / 2}$ binding energy is $98.74 \mathrm{eV}^{41}$

\section{Estimation of the surface oxidation (XPS)}

The XPS chemical analysis of $\mathrm{C}_{7}-\mathrm{NH}_{2}$ and $\mathrm{C}_{11}-\mathrm{NH}_{2}$ surfaces was essential for confirming the bonding of the organic layer as depicted in Figure 1 and published earlier. ${ }^{27,}{ }^{36} \mathrm{We}$ focus now on analyzing the traces of oxide at the interface since they are responsible of most of the electronic surface defects. The Si $2 p$ core-levels spectra for three $\mathrm{C}_{11}$ GOMs are presented in Figure 3. In the present experimental conditions, photoelectrons probe $c a .3 \mathrm{~nm}$ below the surface (detail of the calculation given in the ESI). Deconvolution of the main spectral feature therefore includes the bulk contribution denoted $\mathrm{B}$, and a weaker surface components representing $\mathrm{Si}-\mathrm{C}$ with $+0.3 \mathrm{eV}$ shifts from the bulk peak accounting for $\mathrm{Si}-\mathrm{C}$ bonds formed as the GOMs are grafted via the alkene head. ${ }^{42}$ The $\mathrm{Si}-\mathrm{H}$ component, expected at $+0.14 \mathrm{eV}$ from $\mathrm{B}$ is incorporated in the main peak. ${ }^{43}$ Four Si oxidation states $(+0.9 \mathrm{eV}$ per $\mathrm{O}$ ligand) need to be considered as the samples were shortly exposed to air. ${ }^{41}$ The intensity of these oxidation states is used to measure the impact of the successive treatments on the silicon wafer. For the $\mathrm{C}_{11}$-COEth sample, the bulk line is at $99.50 \mathrm{eV}$ and the sum of the four oxidation states $\Sigma_{\text {ox }}$ corresponds to $9 \%$ of the spectral weight. It can be roughly interpreted as $9 \%$ of the silicon atoms being in an oxidized state. The $4^{\text {th }}$ oxidation state $4+\left(\mathrm{SiO}_{2}\right)$ has a weight of only $1 \%$. For the $\mathrm{C}_{11}-\mathrm{CNH}_{2}$ sample, the bulk line is at $99.57 \mathrm{eV}$, and $\Sigma_{\text {ox }}=8 \%$, similar to the $\mathrm{C}_{11}$-COEth case, but the $4^{\text {th }}$ oxidation state is now more visible (2\%). Finally, after attaching the $\mathrm{Au}$ NPs $\left(\mathrm{C}_{11}-\mathrm{CNH}_{2}-\mathrm{AuNP}\right)$, the bulk line is at $99.63 \mathrm{eV}$ and $\Sigma_{\mathrm{ox}}$ is equal to $11 \%$ (the $4^{\text {th }}$ state weighs now $3 \%$ ). While oxidation progresses slightly with each subsequent treatment, the attack is believed to be local (closer to "pitting", occurring at ill- 
protected spots) rather than homogeneous, and remains at a acceptably low level, even after oversea shipping. The $\mathrm{Si} 2 \mathrm{p}_{3 / 2}$ positions for the two types of GOMs are collected in Table 1. The Si $2 p_{3 / 2}$ values found for the $C_{7}$ GOMs are very close to that found for the $\mathrm{C}_{11}$ one.

\section{Surface band bending measurements (XPS)}

Band bending is observed because electrically active defects are present at the surface. ${ }^{44}$ Indeed, if the functionalization process could saturate every dangling bond, the surface would be electrically neutral, and the semiconductor would be in flatband conditions. The presence of defects leads to the localization of charges at the surface (negative for n-type silicon or positive for p-type), and the formation of a space charge of opposite sign in Si. An electric field appears and the bands bend upward (n-type) or downward (p-type). The absolute position of the $\mathrm{Si} 2 \mathrm{p}_{3 / 2}$ (peak B) is used to determine the surface band bending $q V_{b b}$, which write: $q V_{b b}=$ $\left(E_{F}-E_{v b M}\right)_{B}-\left(E_{F}-E_{v b M}\right)_{S}$

The index $B$ and $S$ designates the bulk and surface, respectively, $E_{F}$ is the Fermi level and $E_{v b M}$ the silicon valence band maximum (see Scheme 1). $\left(E_{F}-E_{v b M}\right)_{B}$ is calculated from the dopant concentration $N_{\mathrm{D}}$ and in the present case $\left(E_{F}-\right.$ $\left.E_{v b M}\right)_{B}=1.05 \mathrm{eV}$. At the surface $\left(E_{F}-E_{v b M}\right)_{S}$ is determined by the measurement of the $\mathrm{BE}$ of $\mathrm{Si} 2 p_{3 / 2}$ core level, $B E\left(\mathrm{Si} 2 p_{3 / 2}\right)^{\text {meas }}$ and the knowledge of the energy difference $\left(E_{v b M}-B E\left(\operatorname{Si~} 2 p_{3 / 2}\right)\right.$, which is constant and equal to 98.74 $\mathrm{eV}^{41}$ Then $q V_{b b}$ writes as:

$q V_{b b}=\left(E_{F}-E_{V B M}\right)_{B}-\left[B E\left(\operatorname{Si~} 2 p_{3 / 2}\right)^{\text {meas }}-\left(E_{V B M}-\right.\right.$

$\left.\left.B E\left(\operatorname{Si~} 2 p_{3 / 2}\right)\right)\right]$

Finally one gets:

$q V_{b b}=99.79 \mathrm{eV}-B E\left(\mathrm{Si} 2 p_{3 / 2}\right)$ meas

For example, for the $\mathrm{C}_{1,} \mathrm{COE}$ measured at $99.49 \mathrm{eV}$ and the $\mathrm{Si}$ bands bent upwards by an amount $q V_{b b}=+0.30 \mathrm{eV}$. Once the band bending is known, the surface charge density $\sigma$ can be derived following the method shown in Sze: ${ }^{45} \sigma=\sqrt{2 \varepsilon_{0} \varepsilon_{S i} q V_{b b} N_{D}}$, where $\varepsilon_{S i}$ is the relative permittivity of $\mathrm{Si}, q V_{\mathrm{bb}}$ is the band bending energy (in $\mathrm{J}$ ) and $N_{D}$ is the donor concentration in the semiconductor. Knowing that the $\mathrm{Si}$ atom surface density is $7.85 \times 10^{14}$ atom $/ \mathrm{cm}^{2}{ }^{45}$ we can express $\sigma$ in term of number of unit charges per Si surface atom $n^{\mathrm{S}}$. (a) Ideal case

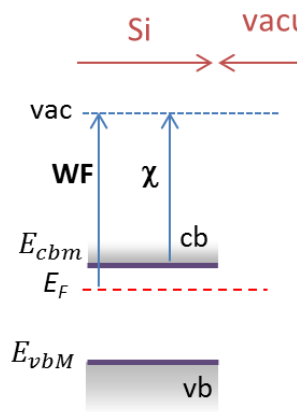

(b) Surface with electrical defects
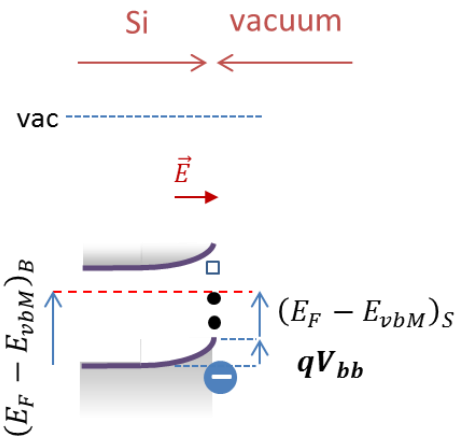

Scheme 1. Band diagram of an $n$-doped silicon surface. In the ideal case (a), when there are no interface states the conduction and valence bands ( $c b$ and $v b$ respectively) are flat near the surface. $\mathrm{WF}$ is the work function (WF $=4.12 \mathrm{eV}$ in our case), $\chi$ is the electronic affinity of the surface and the vacuum level is denoted vac. In the presence of electrically active surface states (b), the defects below the Fermi-level $E_{F}$ are charged and the interface acquires a net negative charge. This charge transfer is compensated by an electric field. The surface band bending can be measured by comparing the measured value of $E_{F}-E_{v b M}$ to the bulk value.

The $q V_{b b}$ and $n^{\mathrm{S}}$ values obtained for our different samples are collected in Table 1. All band bending values are circa $+0.3 \mathrm{eV}$ and for all terminations, $n^{\mathrm{S}}$ is in the range $\sim 3 \times 10^{-3}$ unit charges per Si atom, which corresponds to an amount of unit charge per surface area of $2.4 \times 10^{12} e^{-} / \mathrm{cm}^{2}$. For comparison, transport measurements were carried out with the mercury probe method on a similar $\mathrm{Si} / \mathrm{GOM}$ interface prepared in our group with the same method. An interface state density as low as $1.6 \times 10^{11} \mathrm{~V}^{-}$ $1 / \mathrm{cm}^{2}$ was obtained, which corresponds to an interface density of $\sim 1 \times 10^{11} e^{-} / \mathrm{cm}^{2}$ at an applied bias of $0.5 \mathrm{~V} .{ }^{46,47} \mathrm{We}$ observed 25 times more interface states in our case, possibly due to extra handling needed for these measurements. To obtain a flat band situation, the areal density of defects should be at least one order of magnitude below this value. ${ }^{48,49}$ The electrical defect is likely a triply coordinated silicon $\mathrm{P}_{b}$-like defect, ${ }^{50,51}$ with a double occupancy $\left(\mathrm{Si}^{-}\right)$given the present high n-doping. As the $\sigma$ Si-C bond does not introduce (bonding and antibonding) states in the gap, the origin of electrical defects is very likely related to the unintentional oxidation of the surface, which is hard to fully avoid during air exposure during the required transfer steps. We see no difference in $q V_{B B}$ between the $\mathrm{C}_{7^{-}}$ COEth and the $\mathrm{C}_{11}$-COEth, which confirms that the two molecular layers have very similar structures despite the slightly different hydrosilylation processes (UV or thermal activation). Rather we observe a slight decrease in $q V_{B B}$ (towards a flat band configuration) after $\mathrm{NH}_{2}$ termination. Interestingly, gold nanoparticle deposition does not create new defects.

\section{GOM electronic structure (UPS)}

The UV photoelectron spectra of $\mathrm{C}_{11}$-COEth and $\mathrm{C}_{7}$-COEth GOMs are presented in Figure 4. Note that the He I emission is composed of a main line $\mathrm{I} \alpha$ at $21.21 \mathrm{eV}$ and of a satellite $\mathrm{I} \beta$, shifted to higher energy by $1.854 \mathrm{eV}$ and representing $3 \%$ of the I $\alpha$ intensity; therefore, the corresponding photoemission contribution is subtracted from the raw data for all the spectra in Figure 4. Because the $\mathrm{C} 2 \mathrm{p} / \mathrm{Si} 3 \mathrm{p}$ cross-section ratio is 18.5 at $\mathrm{hv}=21.21 \mathrm{eV},{ }^{52}$ the UPS spectra are dominated by the contribution of the organic layer. The Highest Occupied Molecular Orbital (HOMO) of the organic layer appears in the steep decrease of the UPS signal on the right side of the spectra in Figure 4. It is accompanied by a tail on its low binding energy side, which has previously been assigned to filled induced density of interface states (IDIS). ${ }^{29}$ Typically, the tail extends up to 3.6-3.2 $\mathrm{eV}$ in the GOM gap. Nevertheless, the overall barrier height for electrons between the Si conduction band and the alkyl electronic levels is determined by the edges of the LUMO levels because these states extend throughout the alkyl chain, unlike the tails. ${ }^{29}$ As shown in Figure 4, we determine the HOMO edges graphically at the intersection of 
two lines, one for the HOMO edge and one for the gap state tail. The HOMO edge is $\sim 4.9 \mathrm{eV}$ below the Fermi level for $\mathrm{C}_{11^{-}}$ COEth and for $\mathrm{C}_{7}$-COEth (see also Table 1 for more data). This value is consistent with data obtained by Salomon on a very similar $\mathrm{Si}-\mathrm{C}_{12} \mathrm{H}_{25}$ GOM on n-Si(111). ${ }^{29,53}$ For the $\mathrm{Si}-\mathrm{C}_{11}$ GOM, the addition of the $\mathrm{NH}_{2}$ moiety only slightly shifts the HOMO edge to $5.1-5.2 \mathrm{eV}$.

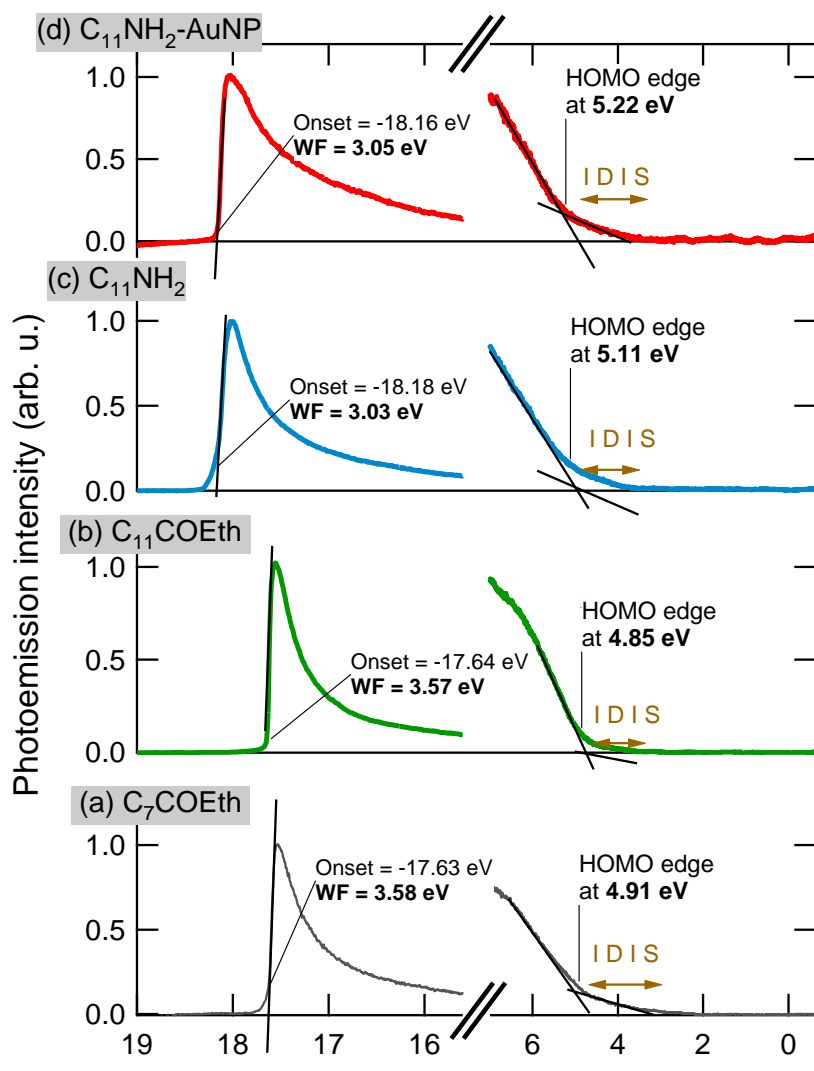

Binding Energy, referenced to Fermi level (eV)

Figure 4. Secondary electron (SE) edges (left part of the spectra) and valence UP Spectra (right spectra) of (a) $\mathrm{C}_{7}$-COEth, (b) $\mathrm{C}_{11}$-COEth, (c) $\mathrm{C}_{11}-\mathrm{NH}_{2}$, and (d) $\mathrm{C}_{11}-\mathrm{NH}_{2}$-AuNP. The cutoffs of the SE curves are indicated by the vertical bars and are used to calculate the work functions of the different organic monolayers. The edges of the UP Spectra correspond to the highest occupied molecular orbital (HOMO)

\section{Work function of the GOM}

The work function (WF) is by definition the energy difference between the vacuum level and $E_{F}$. It is obtained from the secondary electron edge (SE) curve measured with the $\mathrm{He}$ source, as follows:

$W F=h v+K E_{\text {cutoff }}-K E_{\text {Fermi }}$

where $K E_{F e r m i}$ is the kinetic energy of the Fermi level (measured on a clean gold surface) when no bias is applied to the sample (see ESI for more details). The electron affinity $\chi$ is the energy difference between the vacuum level and the minimum of the conduction band $E_{\mathrm{cbm}}$. It is an intrinsic property of the modified Si surface. The expression for $\chi$ is: $\chi=W F-\left(E_{C B M}-E_{F}\right)=W F-\left(E_{g}-\left(E_{F}-E_{V B M}\right)\right)$ where $E_{g}$ is the band gap (1.12 eV).

The secondary electron edges (the excitation source is the $\mathrm{He}$ lamp) are shown for all the samples in Figure $\mathbf{4}$ and in Fig. S4 of the ESI. As the KE scale is referenced to $E_{F}$, the position of the cutoff gives directly the WF. WF and electron affinity $\chi$ are given in Table 1. Note that the SE edges are very sensitive to the homogeneity of the surface. Indeed on a patchy surface the lower cutoff is the averaged cutoff of the different areas, ${ }^{54}$ and the edge of the higher WF region can emerge as a distinct onset. The steepness of the cutoffs in Figure 4 points to a good surface homogeneity. It should also be noted that $\mathrm{C}_{11}$-COEth and $C_{7}$-COEth have the same WF and $\chi$, indicating that there is no effect of the alkyl chain length on the work function in this case. This is in line with previous theoretical studies ${ }^{55}$ as well as experiments with alkanethiols on gold, ${ }^{56}$ showing that the $\mathrm{WF}$ is practically the same for molecules ranging from $\mathrm{CH}_{3}\left(\mathrm{CH}_{2}\right)_{7} \mathrm{SH}$ to $\mathrm{CH}_{3}\left(\mathrm{CH}_{2}\right)_{17} \mathrm{SH}$. The value of $\chi(\sim 3.2 \mathrm{eV})$ is about $1 \mathrm{eV}$ smaller than that of the $\mathrm{H}$-terminated $\mathrm{Si}(111)-1 \times 1$ surface $\left(\sim 4.2 \mathrm{eV}^{57,}{ }^{58}\right)$. On $\mathrm{H}$-terminated $\mathrm{Si}(001)$ surfaces, the attachment of an octadecene GOM leads to a decrease in WF in the range 0.6-0.9 eV. ${ }^{34} \mathrm{~A}$ DFT calculation on a $\left(\mathrm{CH}_{3}\left(\mathrm{CH}_{2}\right)_{4}\right)$ GOM on $\mathrm{Si}(001)$ shows that the WF decrease is due to the substitution of $\mathrm{Si}-\mathrm{H}$ by $\mathrm{Si}-\mathrm{C}$ bonds and to the dipole of the polar groups $\left(\mathrm{CH}_{3}\right)$ within the molecule. ${ }^{34}$ Note that $\chi$ is still $0.5 \mathrm{eV}$ lower than that of $\mathrm{Si}(111)$ surfaces directly terminated by $\mathrm{CH}_{3}$ $\left(3.7 \mathrm{eV}^{34}\right.$ ), possibly due to the dipole (with a normal projection oriented outward) borne by the ethanoate.

Finally, the addition of the terminal amine moiety produces layers with WF (Figure 4) and $\chi$ (Table 1) smaller than that of the original ethanoate GOM. This means that the projection of the dipole of the amine termination (oriented outward) is larger, in absolute value, than that of the ethanoate. However in stark contrast with the ethanoate GOMs, the WF decrease is much smaller for the "short" $\mathrm{C}_{7} \mathrm{NH}_{2}(-0.15 \mathrm{eV})$ than for the "long" $\mathrm{C}_{11} \mathrm{NH}_{2}(-0.48 \mathrm{eV}) \mathrm{GOM}$. This strongly suggests that the amine termination process is much more efficient on the $\mathrm{C}_{11^{-}}$ COEth than on the $\mathrm{C}_{7}$-COEth GOM. A plausible explanation is that the $C_{7}$ is less ordered than the $C_{11}$ GOM, with ethanoate functionalities less available for reaction. This is consistent with the higher resistance of $\mathrm{C}_{7}$-COEth against oxidation in air, compared to that $\mathrm{C}_{11}$ COEth. ${ }^{36}$ 


\section{Journal Name}

\section{ARTICLE}

\begin{tabular}{|c|c|c|c|c|c|c|c|}
\hline Sample & 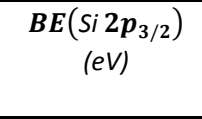 & $\begin{array}{l}\left(E_{F}\right. \\
\left.-E_{V B M}\right) S\end{array}$ & $\begin{array}{c}q V_{b b} \\
(e V)\end{array}$ & $\begin{array}{c}n^{s} \\
\text { e-/Si atom }\end{array}$ & $\begin{array}{l}W F \\
(e V)\end{array}$ & $\begin{array}{l}\chi^{s} \\
(e V)\end{array}$ & $\begin{array}{c}\text { HOMO } \\
\text { edge } \\
(\mathrm{eV})\end{array}$ \\
\hline & Binding energy & & $\begin{array}{c}\text { Band } \\
\text { bending* }\end{array}$ & $\begin{array}{c}\text { Surface } \\
\text { charge } \\
\text { density* }\end{array}$ & $\begin{array}{c}\text { Work } \\
\text { function }\end{array}$ & $\begin{array}{c}\text { electronic } \\
\text { affinity }\end{array}$ & \\
\hline $\mathrm{C}_{7}$-COEth & 99.48 & 0.74 & 0.31 & $3.5 \times 10^{-3}$ & 3.58 & 3.20 & 4.91 \\
\hline $\mathrm{C}_{11}$-COEth & 99.49 & 0.75 & 0.30 & $3.5 \times 10^{-3}$ & 3.57 & 3.20 & 4.85 \\
\hline $\mathrm{C}_{7}-\mathrm{NH}_{2}$ & 99.55 & 0.81 & 0.24 & $3.1 \times 10^{-3}$ & 3.39 & 3.05 & \\
\hline $\mathrm{C}_{11}-\mathrm{NH}_{2}$ & 99.57 & 0.83 & 0.22 & $3.0 \times 10^{-3}$ & 3.03 & 2.74 & 5.11 \\
\hline $\mathrm{C}_{7}-\mathrm{NH}_{2}-\mathrm{AuNP}$ & 99.59 & 0.85 & 0.20 & $2.8 \times 10^{-3}$ & 3.32 & 3.05 & \\
\hline $\mathrm{C}_{11}-\mathrm{NH}_{2}-\mathrm{AuNP}$ & 99.63 & 0.89 & 0.16 & $2.5 \times 10^{-3}$ & 3.05 & 2.82 & 5.22 \\
\hline $\mathrm{Si}(111)-7 \times 7$ & & & & & & $4.16^{\mathrm{e}}$ & \\
\hline $\mathrm{H}-\mathrm{Si}(111)$ & & & & & & $4.17^{\mathrm{a}, \mathrm{b}}$ & \\
\hline $\mathrm{CH}_{3}-\mathrm{Si}(111)$ & & & & & & $3.7^{c}$ & \\
\hline Sputtered Au & & & & & 5.0 & & \\
\hline $\mathrm{Au}(111)$ & & & & & $5.1^{\mathrm{d}}$ & & \\
\hline
\end{tabular}

Table 1. Electronic properties measured for our six samples. $B E\left(\mathrm{Si} 2 p_{3 / 2}\right)$ (referenced to $\mathrm{E}_{\mathrm{F}}$ ) is used to compute $\left(E_{F}-E_{V B M}\right)_{S}$, the (positive) band bending $q V_{b b}$ and the surface charge density expressed in unit charge per Si atom (per mononolayer). (*) These values are averaged over the photoemission probing depth, the "true" $q V_{b b}\left(n^{5}\right)$ values being slightly greater as explained in the SI. The work function WF is obtained from the secondary electron edge cutoff (He I source). It is used to calculate the surface electronic affinity. The HOMO edge is also obtained from the valence band spectra spectra (He I). Values for the electronic affinity are taken from (a) Akremi et al. ${ }^{57}$ (b) Hunger et al. ${ }^{58}$ (c) Hunger et al. ${ }^{59}$ (d) Michaelson et al. ${ }^{60}$ (e) Hollinger et al. ${ }^{61}$

\section{GOM conductivity (Conductive-AFM)}

The electron transport through the GOM was measured using conductive-AFM in contact mode. A typical AFM image is shown in Figure 5 over an area of $300 \times 300 \mathrm{~nm}^{2}$ taken on a $\mathrm{C}_{7^{-}}$ $\mathrm{NH}_{2}$ surface. A series of images was recorded with different values of sample bias (tip grounded) and the topography found to be closely similar to that of Figure 5-a. It displays parallel structures that are $30 \mathrm{~nm}$ wide corresponding to atomic terraces of the $\mathrm{Si}(111)$ surfaces and consistent with the sample miscut $\left(\alpha=0.5^{\circ}\right.$ in the $\langle\overline{11} 2>$ direction yielding $\sim 35 \mathrm{~nm}$ wide terraces). ${ }^{62}$ At $0 \mathrm{~V}$ bias, the RMS roughness of this functionalized surface is $1.3 \mathrm{~nm}$ (see SI for another AFM image). The surface morphology remains unchanged even after scans with $8 \mathrm{~V}$ sample bias. Spectroscopic data were also recorded at various points of the surface and two of them are displayed in Figure 5-b (taken at spots indicated on the image).
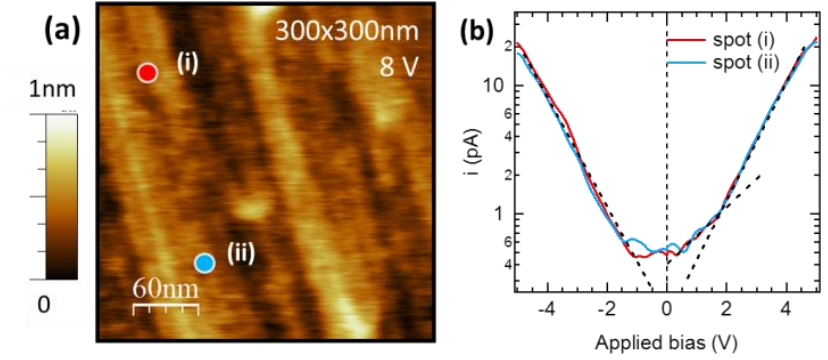

Figure 5. (a) Topographic image $(300 \times 300 \mathrm{~nm})$ obtained with conductive $A F M$, in contact mode for the $\mathrm{C}_{7}-\mathrm{NH}_{2}$ sample. A bias of 8 volt was applied to the sample while scanning. The parallel lines are terraces of the silicon substrate. (b) Spectroscopy curves acquired on the two spots marked on image (a). The curves are averaged over 10 sweeps. They show the two transport regimes discussed in the text.

\section{Discussion}

\section{Surface dipole}

Surface dipole is used to describe the energetic profile that a test charge undergoes when it crosses the interface. It is intrinsically linked to the electronic affinity and the work function of a surface. The formation of an ordered molecular layer creates a surface dipole layer that can either enhance or reduce the ability of extracting electrons from the surface. An 
electron coming from the bulk material will need more energy for crossing the interface if an inward oriented dipole is formed. The surface dipole energy $-e \delta$ is obtained as the difference between the actual electron affinity $\chi^{S}$ and the intrinsic silicon affinity:

$\chi^{S i}:-e \delta=\chi^{S}-\chi^{S i}$

where $e$ is the absolute value of the elementary charge

In eq. (6) a value of $4.05 \mathrm{eV}$ is taken for $\chi^{S i}$, as it is commonly used in evaluating Schottky barriers. ${ }^{45}$

\begin{tabular}{|c|c|c|c|c|c|c|c|c|}
\hline $\begin{array}{c}\text { Terminat } \\
\text { ion }\end{array}$ & $\begin{array}{c}C_{7} O E \\
t h\end{array}$ & $\begin{array}{c}\mathrm{C}_{7} \mathrm{~N} \\
\mathrm{H}_{2} \\
\end{array}$ & $\begin{array}{c}C_{11} O E \\
t h \\
\end{array}$ & $\begin{array}{c}\mathrm{C}_{11} \mathrm{~N} \\
\mathrm{H}_{2} \\
\end{array}$ & $H$ & $\begin{array}{c}\mathrm{CH}_{3} \\
* \\
\end{array}$ & $\begin{array}{c}\mathrm{C}_{5} \mathrm{H} \\
11 \\
\end{array}$ & $\begin{array}{c}\mathrm{C}_{18} \mathrm{H} \\
37 \\
\end{array}$ \\
\hline Ref. & $\begin{array}{l}\text { this } \\
\text { work }\end{array}$ & $\begin{array}{l}\text { this } \\
\text { work }\end{array}$ & $\begin{array}{l}\text { this } \\
\text { work }\end{array}$ & $\begin{array}{l}\text { this } \\
\text { work }\end{array}$ & $\begin{array}{c}\text { Ref } \\
33\end{array}$ & $\begin{array}{c}\text { Ref. } \\
33\end{array}$ & $\begin{array}{c}\text { Ref. } \\
34\end{array}$ & $\begin{array}{c}\text { Ref. } \\
31\end{array}$ \\
\hline $\begin{array}{c}\text { Dipole / } \\
\text { eV }\end{array}$ & -0.85 & -1.0 & -0.85 & -1.31 & $\begin{array}{l}-0 . \\
07\end{array}$ & $\begin{array}{c}-0.4 \\
2\end{array}$ & -0.6 & $\begin{array}{c}-0.5 \\
8\end{array}$ \\
\hline
\end{tabular}

Table 2. Comparison of the molecular surface dipole energies for different molecular functionalizations of the $\mathrm{n}$-doped $\mathrm{Si}(111)$ surfaces. $\mathrm{CH}_{3}$ is marked with an asterisk, because it binds to every silicon atom whereas in all the other surfaces the molecule replaces hydrogen for only half of the silicon surface atoms.

The measured values for the molecular dipole energies presented in Table 2 lead to several conclusions. First, molecular grafting leads to negative dipole energies (all $\chi^{S}$ are smaller than $\chi^{S i}$ ), corresponding to a dipole oriented outward. For all the GOMs studied here, the dipole energy has the same sign (negative) as those found for comparable organic layers. A comparison between $\mathrm{SiC}_{7}$-COEth and $\mathrm{SiC}_{11}$-COEth shows that the dipole energies are identical $(\delta=-0.85 \mathrm{eV})$. Actually it was shown that the potential drop occurs mostly because of the strong polarization of Si-C bond. ${ }^{34}$ The alkyl chain length has a more subtle effect on the WF that was discussed in details by Fagas et al. whose conclusion supports our results of a limited difference in dipolar contribution between 7 and 11 carbon chain lengths. ${ }^{55}$ However, further modification of $\mathrm{SiC}_{7}$-COEth into $\mathrm{SiC}_{7}-\mathrm{NH}_{2}$ increases the absolute value of the dipole energy $(-e \delta=-1.0 \mathrm{eV})$. Calculations further confirm that an amine terminal group greatly contributes to the surface dipole. ${ }^{55,63}$ What might be surprising at first glance is that the effect is still greater for $\mathrm{SiC}_{11}-\mathrm{NH}_{2}(-e \delta=-1.31 \mathrm{eV})$ than for $\mathrm{SiC}_{7}-\mathrm{NH}_{2}$ $(-e \delta=-1.0 \mathrm{eV})$, although this is most likely due to the better ordering of the $\mathrm{C}_{11}$ alky chain compared to that of the $\mathrm{C}_{7}$ one, ultimately leading to a denser layer.

\section{Band diagram of $\mathrm{C}_{7}-\mathrm{NH}_{2}$}

Scheme 2 summarizes the positions of the $\mathrm{SiC}_{7}-\mathrm{NH}_{2}$ surface energy levels using values discussed previously (the other GOMs of the present study behave similarly and the values are summarized in Table 1). The value for the HOMO-LUMO gap was taken from data published elsewhere where the authors used IPES (Inverse Photo-Emission Spectroscopy) to evaluate the LUMO level. ${ }^{29,53,64}$ For example the HOMO-LUMO gap of $\mathrm{Si}-\mathrm{C}_{10} \mathrm{H}_{21}$ is evaluated at $7.3 \mathrm{eV}$ by Kahn's group, and their data show that the gap does not change more than $0.2 \mathrm{eV}$ when the alkyl chain length is increased from $\mathrm{C}_{6}$ to $\mathrm{C}_{18}$. Therefore we retain the value of $7.3 \mathrm{eV}$ for our GOMs. The band diagram represents the energy profile that an electron would feel when moving along the $x$ axis. At around $15 \mathrm{~nm}$ away from the surface (depletion layer), it feels the upward band bending $(0.24 \mathrm{eV})$, then crosses the tunnel barrier (the LUMO edge is at $\sim 2.3 \mathrm{eV}$ above the Fermi level) and is able to move out of the surface if its initial energy is greater than $3.4 \mathrm{eV}$ above the Fermi level (definition of the work function). Moreover, we have shown that the presence of induced density of interface states (denoted IDIS on Scheme 2) strongly affects the transport through the molecular layer.

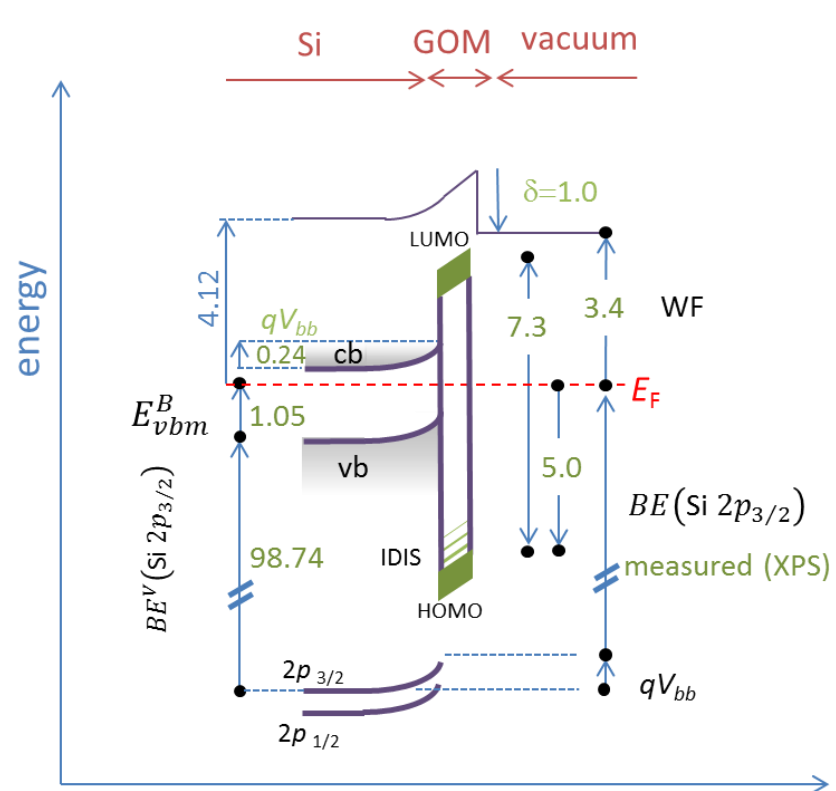

distance

Scheme 2. Band diagram of the $\mathrm{C}_{7}-\mathrm{NH}_{2}$ sample, where an amine terminated molecule with a $\mathrm{C}_{7}$ alkyl chain was grafted on $\mathrm{Si}(111)$. It forms a compact and homogeneous monolayer whose main electronic properties have been measured (values given in eV): the band bending, $\left(E_{\mathrm{bb}}\right)$, the work function (WF), the molecular dipole (回), the position of the highest occupied molecular orbital below the Fermi level (HOMO). IDIS are induced density of interface states. Values are given in $\mathrm{eV}$.

\section{Modification of the surface electronic properties by dispersed AuNPs}

The two amine-terminated surfaces with amine decorated with $8 \mathrm{~nm}$ gold nanoparticles $\left(\mathrm{C}_{7}-\mathrm{NH}_{2}-\mathrm{AuNP}\right.$ and $\left.\mathrm{C}_{11}-\mathrm{NH}_{2}-\mathrm{AuNP}\right)$ have $0.3 \%$ of their surface covered with gold. This is a negligible amount when probed by spectroscopies that average over millimetric areas. Therefore, the influence of gold on the overall electronic surface properties is expected to be negligible (surface density below $10^{10} \mathrm{NP} \mathrm{cm}{ }^{-2}$ ) and this surface is used for checking how the chemical deposition of nanoparticles affects the global electronic properties of the GOM. The work function values reported in Table 1 indicate that the WFs shift by only $-0.07 \mathrm{eV}$ and $+0.02 \mathrm{eV}$ upon deposition of AuNPs on $\mathrm{C}_{7}-\mathrm{NH}_{2}$ and $\mathrm{C}_{11}-\mathrm{NH}_{2}$, respectively. This demonstrates that the chemical treatment applied to the samples for depositing the metallic nanoparticles does not modify significantly the electronic properties of the GOM. Moreover, the relatively low WFs obtained for the GOM $(<3.4 \mathrm{eV})$ compared to gold $(5.1$ $\mathrm{eV}$ ) suggest that, at thermodynamic equilibrium, gold 
nanoparticles will spontaneously accumulate electrons which easily cross the tunnel barrier of the GOM. This charging behavior was recently demonstrated with KPFM by measuring the charge state of individual nanoparticles of different size. For example a $10 \mathrm{~nm}$ nanoparticle accommodates five supplemental electrons. ${ }^{65}$

\section{Transport behavior of the $\mathrm{SiC}_{7}-\mathrm{NH}_{2}$ surface}

The band diagram presented in Scheme 2 provides the shape of the organic electric barrier when no bias is applied to the surface. When the metallic tip of the conductive-AFM is contacted to the layer (see Scheme 3-a), the electrostatic equilibrium of the Metal-Insulator-Semiconductor (MIS) structure changes. ${ }^{45}$ The application of an external bias further modifies the structure, which needs to be addressed for understanding the electronic transport mechanism. Electronic transport through molecular layers is controlled by two parallel active mechanisms: the Schottky barrier inside the semiconductor caused by the band bending near the interface, and the tunnel barrier formed by the organic insulator. From the electrostatic values evaluated above, the profile of the band diagram was drawn numerically using the freely available software designed by Knowlton and Southwick ${ }^{66,67}$. Scheme 3 a shows that, at zero bias when the AFM tip is in contact with the molecular surface, the silicon bands bend upward (inversion regime). The depletion layer spans over $20 \mathrm{~nm}$. When a moderate positive voltage is applied to the semiconductor (e.g., when the AFM tip is grounded), the transport occurs by tunneling through the molecular barrier. Scheme 3-c shows that the electrons have to cross a trapezoidal barrier, in which case the transport is described by ${ }^{45,68-71}$

$$
I \propto V \exp \left(-\frac{2 d \sqrt{2 m^{*} \phi}}{\hbar}\right)
$$

Equation 7

where $d$ is the barrier thickness, $m^{*}$ is the electron effective mass, and $\phi$ is the barrier height.
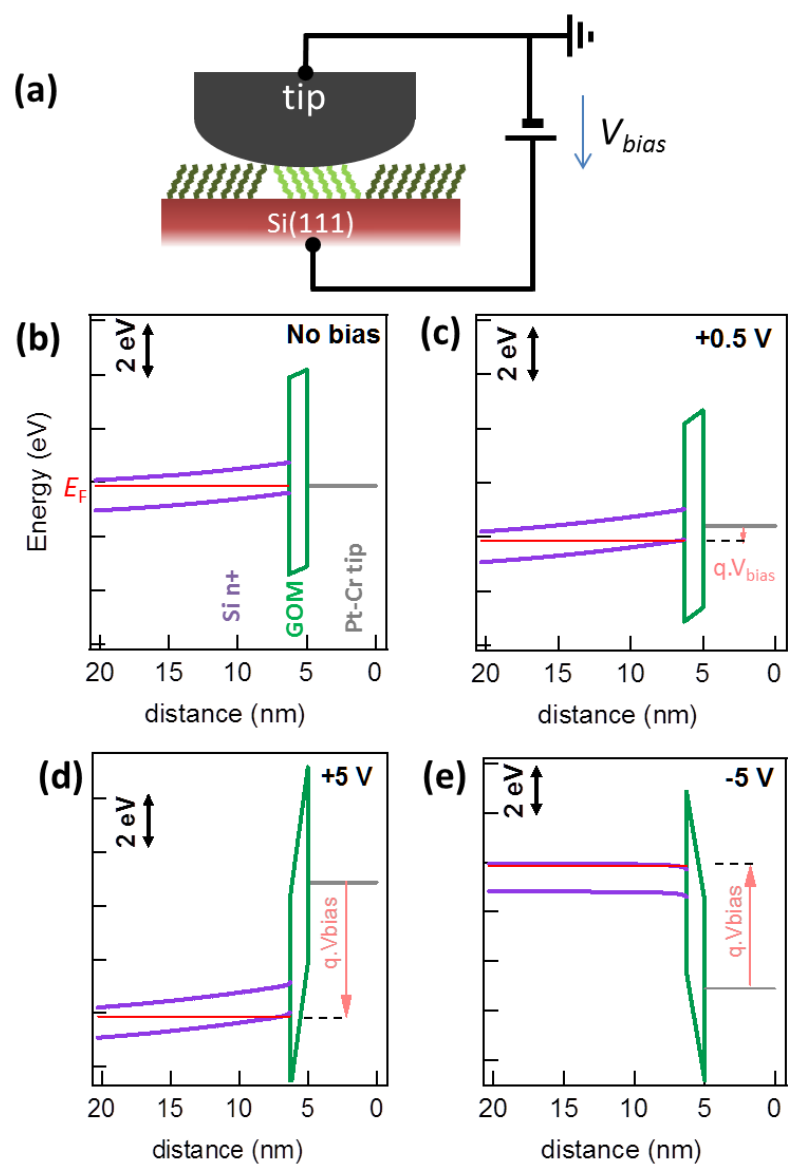

Scheme 3. Band diagram drawn when the tip of the conductive AFM is in contact with the $\mathrm{Si}-\mathrm{C}_{7} \mathrm{NH}_{2} \mathrm{GOM}$ (a). Calculations are done with the parameters discussed above. At zero sample bias (b) the silicon is already in inversion. With moderate sample bias $(+0.5 \mathrm{~V}(\mathrm{c}))$ the barrier is trapezoidal (tunneling regime) whereas at strong bias ( $d \&$ e) the barrier is triangular and the transport is dominated by thermionic emission.

However, when the bias is strongly increased (positive bias), the electric field across the GOM becomes important and the electrons face a triangular barrier. The transport starts being dominated by field emission (Fowler-Nordheim regime), as depicted in Scheme 3-c \& d, and the current-voltage follows the relationship (positive bias): ${ }^{68}$

$I \propto V^{2} \exp \left(-\frac{4 d \sqrt{2 m^{*} \phi^{3}}}{3 \hbar \mathrm{qV}}\right)$

Equation 8

A Fowler-Nordheim plot is the graph of $\ln \left(I / V^{2}\right)$ against $1 / V$ and is given in Figure 6. From Eq. (7), it obvious that $\ln \left(\frac{I}{V^{2}}\right) \propto \frac{1}{V}-2 \frac{d}{\hbar} \sqrt{2 m^{*} \phi}$ for a tunneling regime and therefore we expect a linear evolution with a positive slope. This tunneling regime is identified in Figure 6 for biases comprised between $-2.2 \mathrm{~V}$ and $1.9 \mathrm{~V}$ (large values of $1 / \mathrm{V}$ ). On the other hand, Eq. (8) shows that a linear evolution is also expected for strong positive biases, but with a negative slope. This trend is confirmed by our experiments for values of $1 / \mathrm{V}$ smaller than 1/1.9 Volt $^{-1}$. Figure 6 clearly shows the transition between the tunneling and the field emission regimes, corresponding to the minima at -2.2 and $+1.9 \mathrm{~V}$. Moreover, the intersection with the vertical axis occurs at $-2 \frac{d}{\hbar} \sqrt{2 m^{*} \phi}$ for the low bias regime and the barrier height $\phi$ can be evaluated (with $d=1.3 \mathrm{~nm}$ and 
$\left.m^{*}=0.25 m_{\mathrm{e}}{ }^{53}\right)$. For positive bias, we calculate $\phi=0.06 \mathrm{eV}$ From the simplified diagram of Scheme 3-c, we expect a value of $\sim 2.5 \mathrm{eV}$. The discrepancy between the experimental and calculated values points to the complex transport mechanism. It shows that the Induced Density of Interfaces States detected by our UPS spectra provide additional low energy paths for the electron to cross the tunnel barrier. Moreover the simplified diagram of Scheme $\mathbf{3}$ is calculated for a planar MIS structure, whereas the tip of the AFM cannot be represented with an infinite plane. Curvature will decrease the amount of band bending and therefore also the overall barrier height. The consideration of all these parameters exceeds the scope of the present study.

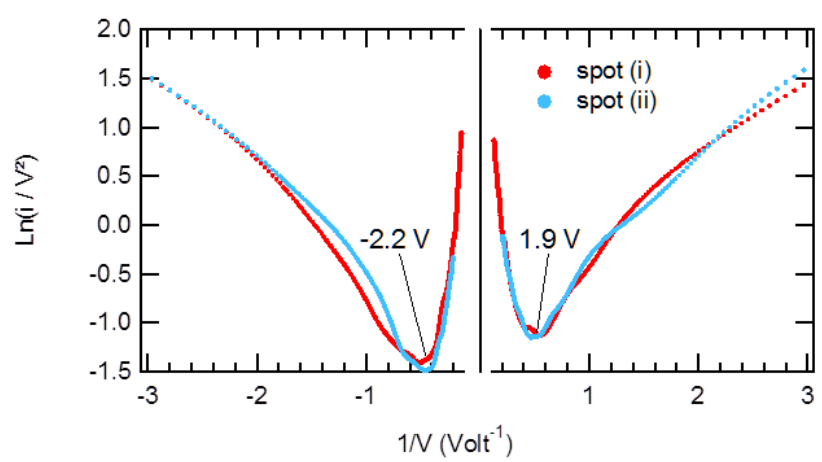

Figure 6. Fowler-Nordheim plot where the transition between the tunneling regime (low bias regime) and the field emission (high bias) regime appears as a minimum in the graph. The two curves correspond to the two spots identified in Fig. 5.

\section{Conclusion}

The complete energy diagram was derived for six organic alkylchain monolayers directly grafted on oxide-free, atomically flat $\mathrm{H}$-terminated $\mathrm{Si}(111)$ surfaces. As shown by XPS, the GOMs clearly provide a barrier to oxidation and other chemical reactions during subsequent chemical processes: replacement of ethanoate by the amine head, AuNP deposition, and inevitable exposure to air. We established and analyzed in detail the band bending diagram of the GOMs on silicon and used it to explain the electronic transport properties of the GOMs. The conclusions derived from this work demonstrate that the surfaces functionalized by hydrosilylation are among the best candidates for building tailored hybrid nano-devices where the organic monolayers provide the electrically active layer. As theoreticians start providing methods for optimizing $a$ priori the band diagram of a grafted organic monolayer ${ }^{72}$ and other experimental studies continue to develop new approaches for fabricating MIS structures with organic monolayers, ${ }^{73}$ GOM will likely become an essential component for the next generation nano-electronic devices.

\section{Acknowledgements}

LC acknowledges support by NSF-CHE (1300180), a Chateaubriand Fellowship and a Nanotwinning FP7 grant, NN294952. Y. Z. and M. S. acknowledge support by the "SelfAssembly of Organic/Inorganic Nanocomposite Materials" program, Office of Science, the Office of Basic Energy Sciences (BES), Materials Sciences and Engineering (MSE) Division of the U.S. Department of Energy (DOE) under Contract No. DE-ACO2$05 \mathrm{CH} 11231$. It used resources of the Molecular Foundry, a DOE Office of Science user facility.

\section{Notes and references}

1. J. C. Cuevas and E. Scheer, Molecular Electronics, World Scientific Publishing Company, London, 2010.

2. M. Ratner, Nat Nano, 2013, 8, 378-381.

3. L. Sun, Y. A. Diaz-Fernandez, T. A. Gschneidtner, F. Westerlund, S. Lara-Avila and K. Moth-Poulsen, Chemical Society Reviews, 2014, 43, 7378-7411.

4. G. Comtet, G. Dujardin, L. Hellner, M. Lastapis, M. Martin, A. Mayne and D. Riedel, Philosophical Transactions of the Royal Society A: Mathematical, Physical and Engineering Sciences, 2004, 362, 1217-1226.

5. A. Y. Anagaw, R. A. Wolkow and G. A. DiLabio, J. Phys. Chem. C, 2008, 112, 3780-3784.

$6 . \quad$ S. F. Bent, Surf. Sci., 2002, 500, 879-903.

7. S. Lenfant, D. Guerin, F. T. Van, C. Chevrot, S. Palacin, J. P. Bourgoin, O. Bouloussa, F. Rondelez and D. Vuillaume, J. Phys. Chem. B, 2006, 110, 13947-13958.

8. A. Vilan, O. Yaffe, A. Biller, A. Salomon, A. Kahn and D. Cahen, Advanced Materials, 2010, 22, 140-159.

9. R. Har-Lavan, O. Yaffe, P. Joshi, R. Kazaz, H. Cohen and D. Cahen, AIP Advances, 2012, 2, 012164.

10. K. Uosaki, H. Fukumitsu, T. Masuda and D. Qu, Phys. Chem. Chem. Phys., 2014, 16, 9960-9965.

11. A. B. Fadjie-Djomkam, S. Ababou-Girard and C. Godet, J. Appl. Phys., 2012, 112, 113701-113711.

12. J. Terry, M. R. Linford, C. Wigren, R. Cao, P. Pianetta and C. E. D. Chidsey, Appl. Phys. Let., 1997, 71, 1056-1058.

13. R. L. Cicero, M. R. Linford and C. E. D. Chidsey, Langmuir, 2000, 16, 5688-5695.

$14 . \quad$ O. Seitz, T. Boecking, A. Salomon, J. J. Gooding and D. Cahen, Langmuir, 2006, 22, 6915-6922.

15. L. C. P. M. de Smet, A. V. Pukin, Q.-Y. Sun, B. J. Eves, G. P. Lopinski, G. M. Visser, H. Zuilhof and E. J. R. Sudhölter, Appl. Surf. Sc., 2005, 252, 24-30.

16. A. Faucheux, A. C. Gouget-Laemmel, C. Henry de Villeneuve, R. Boukherroub, F. Ozanam, P. Allongue and J. N. Chazalviel, Langmuir, 2006, 22, 153-162.

17. S. Fellah, R. Boukherroub, F. Ozanam and J. N. Chazalviel, Langmuir, 2004, 20, 6359-6364.

18. R. Boukherroub, Current Opinion in Solid State and Materials Science, 2005, 9, 66-72.

19. Y. Li, S. Calder, O. Yaffe, D. Cahen, H. Haick, L. Kronik and H. Zuilhof, Langmuir, 2012, 28, 9920-9929.

20. P. Thissen, O. Seitz and Y. J. Chabal, Progr. Surf. Sci., 2012, 87, 272-290.

21. S. R. Puniredd, O. Assad, T. Stelzner, S. Christiansen and H. Haick, Langmuir, 2011, 27, 4764-4771.

22. S. R. Puniredd, S. Jayaraman, S. H. Yeong, C. Troadec and M. P. Srinivasan, The Journal of Physical Chemistry Letters, 2013, 4, 1397-1403.

23. S. Lee, J. Lee, H. Lee, Y. J. Yuk, M. Kim, H. Moon, J. Seo, Y. Park, J. Y. Park, S. H. Ko and S. Yoo, Organic Electronics, 2013, 14, 3260-3266.

24. O. Yaffe, T. Ely, R. Har-Lavan, D. A. Egger, S. Johnston, H. Cohen, L. Kronik, A. Vilan and D. Cahen, The Journal of Physical Chemistry C, 2013, 117, 22351-22361.

25 F. Wei, B. Sun, Y. Guo and X. Zhao, Biosens Bioelectron, 2003, 18, 1157-1163. 
26. W. Cai, J. Peck, D. Van der Weide and R. Hamers, Biosens Bioelectron, 2004, 19, 1013-1019.

27. L. Caillard, O. Seitz, P. Campbell, R. Doherty, A.-F Lamic-Humblot, E. Lacaze, Y. J. Chabal and O. Pluchery, Langmuir, 2013, 29, 5066-5073.

28. H. Haick, J. Ghabboun, O. Niitsoo, H. Cohen, D. Cahen, A. Vilan, J. Y. Hwang, A. Wan, F. Amy and A. Kahn, J. Phys. Chem. $B, 2005,109,9622-9630$.

29. L. Segev, A. Salomon, A. Natan, D. Cahen, L. Kronik, F. Amy, C. K. Chan and A. Kahn, Phys. Rev. B, 2006, 74, 165323

30. F. Thieblemont, O. Seitz, A. Vilan, H. Cohen, E. Salomon, A. Kahn and D. Cahen, Advanced Materials, 2008, 20, 3931.

31. C. A. Hacker, Solid-State Electron., 2010, 54, 1657-1664.

32. J. J. Gallet, F. Bournel, F. Rochet, U. Köhler, S. Kubsky, M. G. Silly, F. Sirotti and D. Pierucci, The Journal of Physical Chemistry C, 2011, 115, 7686-7693.

33. D. C. Gleason-Rohrer, B. S. Brunschwig and N. S. Lewis, The Journal of Physical Chemistry C, 2013, 117, 18031-18042.

34. I. Magid, L. Burstein, O. Seitz, L. Segev, L. Kronik and Y. Rosenwaks, J. Phys. Chem. C, 2008, 112, 7145-7150.

35. Y. Zhang, D. Ziegler and M. Salmeron, ACS Nano, 2013, 7, 8258-8265.

36. L. Caillard, S. Sattayaporn, A.-F. Lamic-Humblot, S Casale, P. Campbell, Y. J. Chabal and O. Pluchery, Nanotechnology, 2015, 26, 065301.

37. D. Aureau, Y. Varin, K. Roodenko, O. Seitz, O. Pluchery and Y. J. Chabal, J. Phys. Chem. C, 2010, 114, 14180-14186.

38. G. S. Higashi, Y. J. Chabal, G. W. Trucks and K. Raghavachari, Appl. Phys. Let., 1990, 56, 656-658.

39. E. C. Stathis and A. Fabrikanos, Chem. Ind., 1958, 860-

861.

40. J. Kimling, M. Maier, B. Okenve, V. Kotaidis, H. Ballot and A. Plech, J. Phys. Chem. B, 2006, 110, 15700-15707.

41. F. J. Himpsel, G. Hollinger and R. A. Pollak, Phys. Rev. B, 1983, 28, 7014-7018.

42. L. J. Webb, D. J. Michalak, J. S. Biteen, B. S. Brunschwig A. S. Y. Chan, D. W. Knapp, H. M. Meyer, E. J. Nemanick, M. C. Traub and N. S. Lewis, J. Phys. Chem. B, 2006, 110, 23450-23459. 43. K. Hricovini, R. Günther, P. Thiry, A. Taleb-Ibrahimi, G. Indlekofer, J. E. Bonnet, P. Dumas, Y. Petroff, X. Blase, X. Zhu, S. G. Louie, Y. J. Chabal and P. A. Thiry, Phys. Rev. Lett., 1993, 70, 1992-1995

44. Y. Zhang, D. Zherebetskyy, N. D. Bronstein, S. Barja, L. Lichtenstein, D. Schuppisser, L.-W. Wang, A. P. Alivisatos and M. Salmeron, Nano Lett., 2015, 15, 3249-3253.

45. S. M. Sze, Physics of Semiconductor Devices, John Wiley \& Sons, New-York, Second Edition edn., 1981.

46. W. Peng, O. Seitz, R. A. Chapman, E. M. Vogel and Y. J. Chabal, Appl. Phys. Let., 2012, 101, 051605-051605.

47. The work function of mercury is $4.5 \mathrm{eV}$, therefore the system studied by Peng et al. is flatband at zero applied bias. To obtain similar band bending as in our case, and compare the interface state density we use their $D_{i t}$ value at $0.3 \mathrm{~V}$ which is $1.6 \times 10^{11}$ interface state per volt and per $\mathrm{cm}^{2}$.

48. A. Zur, T. C. McGill and D. L. Smith, Phys. Rev. B, 1983, 28, 2060-2067.

49. F. J. Himpsel, B. S. Meyerson, F. R. M. Feely, J. F. Morar, A. Taleb-Ibrahimi and J. A. Yarmoff, Varenna, 1988.

50. P. J. Caplan, E. H. Poindexter, B. E. Deal and R. R. Razouk, J. Appl. Phys., 1979, 50, 5847-5854.

51. P. Broqvist, A. Alkauskas and A. Pasquarello, Phys. Rev. $B, 2008,78,075203$.

52. J. J. Yeh and I. Lindau, Atomic Data and Nuclear Data Tables, 1985, 32, 1-155.

53. A. Salomon, T. Boecking, O. Seitz, T. Markus, F. Amy, C. Chan, W. Zhao, D. Cahen and A. Kahn, Advanced Materials, 2007, 19, 445-450.
54. N. Bundaleski, J. Trigueiro, A. G. Silva, A. M. C Moutinho and O. M. N. D. Teodoro, J. Appl. Phys., 2013, 113, 183720.

55. H. H. Arefi, M. Nolan and G. Fagas, The Journal of Physical Chemistry C, 2015, 119, 11588-11597.

56. D. M. Alloway, M. Hofmann, D. L. Smith, N. E. Gruhn, A L. Graham, R. Colorado, V. H. Wysocki, T. R. Lee, P. A. Lee and N. R. Armstrong, J. Phys. Chem. B, 2003, 107, 11690-11699.

57. A. Akremi, J. P. Lacharme and C. A. Sébenne, Surf. Sci. 1998, 402-404, 746-750.

58. R. Hunger, C. Pettenkofer and R. Scheer, J. Appl. Phys. 2002, 91, 6560-6570.

59. R. Hunger, R. Fritsche, B. Jaeckel, W. Jaegermann, L. J. Webb and N. S. Lewis, Phys. Rev. B, 2005, 72, 045317-045323.

60. H. B. Michaelson, J. Appl. Phys., 1977, 48, 4729-4733.

61. G. Hollinger and F. J. Himpsel, Journal of Vacuum Science \& Technology A, 1983, 1, 640

62. For a given sample miscut $\alpha$, the width of terraces a is expected to be $35 \mathrm{~nm}$, since $a=h / \tan \alpha$, where $h$ is the height of $\mathrm{Si}(111)$ step $(h=0.313 \mathrm{~nm})$. This relatively high miscut was not intentional and results from the batch of wafers used for these experiments.

63. H. H. Arefi and G. Fagas, The Journal of Physical Chemistry C, 2014, 118, 14346-14354.

64. S. Avasthi, Y. Qi, G. K. Vertelov, J. Schwartz, A. Kahn and J. C. Sturm, Surf. Sci., 2011, 605, 1308-1312.

65. Y. Zhang, O. Pluchery, L. Caillard, A.-F. Lamic-Humblot, S. Casale, Y. J. Chabal and M. Salmeron, Nano Letters, 2015, 15, 51-55.

66. R. G. Southwick and W. B. Knowlton, Device and Materials Reliability, IEEE Transactions on, 2006, 6, 136-145.

67. B. Knowlton, http://nano.boisestate.edu/researchareas/multi-dielectric-energy-band-diagram-program/)

68. J. M. Beebe, B. Kim, J. W. Gadzuk, C. Daniel Frisbie and J. G. Kushmerick, Phys. Rev. Lett., 2006, 97, 026801.

69. S. Y. Sayed, J. A. Fereiro, H. Yan, R. L. McCreery and A. J. Bergren, Proceedings of the National Academy of Sciences, 2012, 109, 11498-11503.

70. H. Hamoudi, K. Uosaki, K. Ariga and V. A. Esaulov, RSC Advances, 2014, 4, 39657-39666.

71. A. Salomon, T. Boecking, C. K. Chan, F. Amy, O Girshevitz, D. Cahen and A. Kahn, Phys. Rev. Lett., 2005, 95 266807.

72. B. Kretz, D. A. Egger and E. Zojer, Advanced Science, 2015, 2, 1400016-1400024.

73. L. M. Ballesteros, S. Martín, J. Cortés, S. MarquésGonzález, F. Pérez-Murano, R. J. Nichols, P. J. Low and P. Cea, Advanced Materials Interfaces, 2014, 1, doi: 10.1002/admi.201400128. 